\title{
ANOTHER LOOK AT TRADING COSTS AND SHORT- TERM REVERSAL PROFITS
}

\begin{abstract}
Several studies report that abnormal returns associated with short-term reversal investment strategies diminish once trading costs are taken into account. We show that the impact of trading costs on the strategies' profitability can largely be attributed to excessively trading in small cap stocks. Limiting the stock universe to large cap stocks significantly reduces trading costs. Applying a more sophisticated portfolio construction algorithm to lower turnover reduces trading costs even further. Our finding that reversal strategies generate 30 to 50 basis points per week net of trading costs poses a serious challenge to standard rational asset pricing models. Our findings also have important implications for the understanding and practical implementation of reversal strategies.
\end{abstract}

JEL Classification: G11, G12, G14

Keywords: market efficiency, anomalies, short-term reversal, portfolio construction, market impact, transaction costs, liquidity 


\section{INTRODUCTION}

A growing body of literature argues that the short-term reversal anomaly (i.e., the phenomenon that stocks with relatively low (high) returns over the past month or week earn positive (negative) abnormal returns in the following month of week) documented by Rosenberg, Reid, and Lanstein (1985), Jegadeesh (1990) and Lehman (1990) can be attributed to trading frictions in securities markets that weaken the arbitrage mechanism. Kaul and Nimalendran (1990), Conrad, Kaul and Nimalendran (1991) and Ball, Kothari, and Wasley (1995) report that most of short-term reversal profits fall within bid-ask bounds. And more recently, Avramov, Chordia and Goyal (2006) evaluate the profitability of reversal investment strategies net of trading costs using the model of Keim and Madhavan (1997). They find that reversal strategies require frequent trading in disproportionately high-cost securities such that trading costs prevent profitable strategy execution. Based on these results one might conclude that the abnormal returns associated with reversal investment strategies that are documented in earlier studies create an illusion of profitable investment strategies when, in fact, none exist. The seemingly lack of profitability of reversal investment strategies is consistent with market efficiency.

In this study we show that this argument is not necessarily true. We argue that the reported impact of trading costs on reversal profits can largely be attributed to excessively trading in small cap stocks. When stocks are ranked on past returns, stocks with the highest volatility have the greatest probability to end up in the extreme quantiles. These stocks are typically the stocks with the smallest market capitalizations. Therefore a portfolio that is long-short in the extreme quantiles is typically invested in the smallest stocks. 
However, these stocks are also the most expensive to trade and reversal profits may be fully diminished by the disproportionally higher trading costs.

At the same time, the turnover of standard reversal strategies is excessively high. Reversal portfolios are typically constructed by taking a long position in loser stocks and short position in winner stocks based on past returns. Then, at a pre-specified interval the portfolios are rebalanced and stocks that are no longer losers are sold and replaced by newly bottomranked stocks. Vice versa, stocks that are no longer winners are bought back and replaced by newly top-ranked stocks. While this approach is standard in the stream of literature on empirical asset pricing to investigate stock market anomalies, it is suboptimal when the profitability of an investment strategy is evaluated and trading costs are incorporated.

To investigate the impact of small cap stocks and rebalancing rules on the profitability of reversal strategies, we design and test three hypotheses: first, we gauge the profitability of reversal strategies applied to various market cap segments of the U.S. stock market. Our hypothesis is that the reported impact of trading costs on reversal profits can largely be attributed to excessively trading in small cap stocks and that limiting the stock universe to large cap stocks significantly reduces trading costs. Our second hypothesis is that trading costs can be reduced even further without giving up too much of the gross reversal profits when a slightly more sophisticated portfolio construction algorithm is applied. Third, we extend our analyses of reversal profits within different segments of the U.S. market with an analysis across different markets and evaluate the profitability of reversal strategies in European stocks markets. Our hypothesis is that trading costs have a larger 
impact on reversal profits in European markets since these markets are less liquid. For robustness, we also evaluate reversal profits across various market cap segments of the European stock markets.

Throughout our study we use trading cost estimates resulting from the Keim and Madhavan (1997) model and estimates that were provided to us by Nomura Securities, one of world's largest stock brokers. Consistent with Avramov, Chordia and Goyal (2006) we find that the profits of a standard reversal strategy are smaller than the likely trading costs for a broad universe that includes small cap stocks. At the same time we find that the impact of trading costs on short-term reversal profits becomes substantially lower once we exclude small cap stocks that are the most expensive to trade. In fact, when we focus on the largest U.S. stocks we document significant reversal profits up to 30 basis points per week.

When we also apply a slightly more sophisticated portfolio construction algorithm and do not directly sell (buy back) stocks that are no longer losers (winners) but wait until these stocks are ranked among the top (bottom) 50 percent of stocks based on past returns, the turnover and trading costs of the strategy more than halve and we find even larger reversal profits up to 50 basis points per week. This number is highly significant from both a statistical and an economical point of view.

Additionally, we find that trading costs have a larger impact on reversal profits in European markets. While standard reversal strategies based on a broad universe of European stocks yield gross returns of 50 basis points per week, their returns net of trading costs are highly negative. Once we exclusively focus on the largest stocks and apply the "smart" portfolio 
construction rules, we document significantly positive net reversal profits up to 20 basis points per week.

In addition, we look at various other aspects of the reversal strategy to evaluate if the strategy can be applied in practice. Amongst others, we document that the reversal effect can be exploited by a sizable strategy with a trade size of one million USD per stock; and that the strategy also earned large positive net returns over the post-decimalization era of U.S. stock markets.

We deem that our study contributes to the existing literature in at least two important ways. First of all, our finding that reversal strategies yield significant returns net of trading costs presents a serious challenge to standard rational asset pricing models. Our findings also have important implications for the practical implementation of reversal strategies. The key lesson is that investors striving to earn superior returns by engaging in reversal trading are more likely to realize their objectives by using portfolio construction rules that limit turnover and by trading in liquid stocks with relatively low trading costs. Our study adds to the vast amount of literature on short-term reversal or contrarian strategies [see, e.g., Fama (1965), Jegadeesh (1990), Lehmann (1990), Lo and MacKinlay (1990), Jegadeesh and Titman (1995a,b), Chan (2003), Subrahmanyam (2005), and Gutierrez and Kelley (2008)]. Our work is also related and contributes to a recent strand in the literature that re-examines market anomalies after incorporating transaction costs [see, e.g., Lesmond, Schill, and Zhou (2004), Korajczyk and Sadka (2004), Avramov, Chordia, and Goyal (2006) and Chordia, Goyal, Sadka, Sadka, and Shivakumar, (2009)]. 
Our results also have important implications for several explanations that have been put forward in the literature to explain the reversal anomaly. In particular, our finding that net reversal profits are large and positive among large cap stocks over the most recent decade in our sample, during which market liquidity dramatically increased, rules out the explanation that reversals are induced by inventory imbalances by market makers and that the contrarian profits are a compensation for bearing inventory risks [see, e.g., Jegadeesh and Titman (1995b)]. Also, our finding that reversal profits are not convincingly larger for the 1,500 largest U.S. stocks than for the 500 and even 100 largest stocks is inconsistent with the notion that nonsynchronous trading contributes to contrarian profits [see, e.g., Lo and MacKinlay (1990) and Boudoukh, Richardson, and Whitelaw (1994)] as this explanation predicts a size-related lead-lag-effect in stock returns and higher reversal profits among small cap stocks.

Our second main contribution is that we not only employ the trading costs estimates from the Keim and Madhavan (1997) model that are typically used in this stream of literature, but that we also use estimates that were provided to us by Nomura Securities. Despite the fact that most researchers now seem to acknowledge the importance of taking trading costs into account when evaluating the profitability of investment strategies, only very little is documented in the academic literature on how these costs should be modelled. Perhaps the most authoritative research in this field is the work of Keim and Madhavan (1997) who modelled market impact as well as commission costs for trades for NYSE-AMEX stocks during 1991 to 1993. However, since markets have undergone important changes over time one 
may wonder if the parameter estimates of Keim and Madhavan can be used to estimate trading costs accurately also over more recent periods. Another concern with the Keim and Madhavan model relates to the functional form that is imposed on the relation between market capitalization and trading costs. Later in the paper we provide some detailed examples which indicate that trading costs estimates resulting from the Keim and Madhavan model should be interpreted with caution in some cases because of these issues. For example, the model systematically yields negative cost estimates for a large group of stocks over the most recent period. We believe that our study makes a significant contribution to the literature on evaluating the profitability of investment strategies by providing a comprehensive overview of trading costs estimates from Nomura Securities for S\&P1500 and S\&P500 stocks during the period 1990 to 2009 . Moreover, the trading cost schemes we publish in this study are set up in such a way that other researchers can employ them in their studies as the schemes merely require readily-available volume data for their usage.

An additional attractive feature of the trading cost model used by Nomura Securities is that it has also been calibrated using European trade data. This enables us to investigate trading costs and reversal profits in European equity markets as well. To our best knowledge, this study is the first to provide a comprehensive overview of trading costs and to investigate trading cost impact on reversal profits in European equity markets.

\section{STOCK DATA}


For our U.S. stock data we use return data for the 1,500 largest stocks that are constituents of the Citigroup U.S. Broad Market Index (BMI) during the period January 1990 and December 2009. We intentionally leave out micro cap stocks from our sample that are sometimes included in other studies to ensure that our findings are not driven by market micro-structure concerns. For our European stock data we use return data for the 1,000 largest stocks that were constituents of the Citigroup European Broad Market Index during the period January 1995 and December 2009. The reason why we start in 1995 instead of 1990 as we do in our analysis using U.S. data is that the trading cost model of Nomura is not accurately calibrated to estimate trading costs for European stocks before 1995. Daily stock returns including dividends, market capitalizations and price volumes are obtained from the FactSet Global Prices database. ${ }^{1}$

We visually inspect various measures of liquidity for both stock markets, including market capitalization, daily trading volumes, turnover, and Amihud's (2002) illiquidity measure. ${ }^{2}$ When we compare our U.S. sample to the one studied by Avramov, Chordia, and Goyal (2006), our sample seems to be more liquid. For example, when we consider the stocks' illiquidity in our sample we find a median illiquidity measure of 0.02 in 1990 that decreases to 0.001 in 2009. Avramov, Chordia, and Goyal (2006) report this figure to be 0.05 for the most liquid group of stocks in their sample. For the least liquid group of stocks the authors even report average illiquidity of 10.8. This figure basically implies that the price impact resulting from trading one million USD in these stocks is roughly 10 percent. We do not observe such large numbers

\footnotetext{
${ }^{1}$ FactSet Global Prices is a hiqh-quality securities database offered by FactSet Research Systems Inc.

${ }^{2}$ For the sake of brevity, we do not report these results in tabular form.
} 
for illiquidity in our sample. We believe that the largest portion of the differences in liquidity between our sample and that of Avramov, Chordia and Goyal (2006) can be attributed to the fact that we investigate a more recent period of time during which markets were much more liquid. In addition, our sample does not include micro cap stocks.

Next, we compare the liquidity of the European stock markets to that of the U.S. stock market. It appears that the European markets also have been liquid over our sample period, but that the illiquidity level is higher than for the U.S. market: the median illiquidity measure is 0.004 in 2009 for the European markets, while this figure is 0.001 for the U.S. stocks.

\section{TRADING COST ESTIMATES}

Consistent with most of the literature we use the trading cost model of Keim and Madhavan (1997) to estimate net reversal profits for our first analyses. These trading cost estimates include commissions paid as well as an estimate of the price impact of the trades. Keim and Madhavan regress total trading costs on several characteristics of the trade and the traded stock. Appendix A provides a more detailed description of the Keim and Madhaven model.

An important caveat that should be taken into account when using the Keim and Madhavan (1997) model is that its coefficients are estimated over the period January 1991 through March 1993. Since markets have undergone important changes over time one may wonder if estimates resulting from the Keim and Madhavan model are also accurate over more recent periods. For example, after two centuries pricing in fractions, the NYSE and AMEX converted all of their stocks to decimal pricing in 2001 which led to a large 
decrease in bid-ask spreads on both exchanges. Also, increasing trading volumes over time; more competition among stock brokers; and technological improvements may have had an important impact on bid-ask spreads, market impact costs and commissions.

To cope with this issue, we asked one of world's largest stock brokers, Nomura Securities, if they could provide us with trading cost estimates for stocks that are constituents of the S\&P1500 index over our sample period January 1990 through December 2009. Appendix B provides a detailed description of the Nomura model. As estimates for broker commissions a 5 basis points rate per trade is used during the 1990s and a 3 basis points rate over the most recent 10 years of our sample period.

An important aspect that came to light in our conversations with the researchers from Nomura is that trading style may have a significant impact on trading costs. For example, technical traders that follow momentum-like strategies and have a great demand for immediacy typically experience large bid-ask costs since the market demand for the stocks they aim to buy is substantially larger than the supply, and vice versa for sell transactions. In their study, Keim and Madhavan (1997) also find that technical traders generally experience higher trading costs than traders whose strategies demand less immediacy like value traders or index managers. The researchers of Nomura told us that the trading costs that are associated with a reversal strategy are likely to be somewhat lower than the estimates they provided since a reversal strategy by nature buys (sells) stocks for which the market supply (demand) is larger than the demand (supply). However, they could not provide us with an exact number to correct for this feature of 
reversal strategies. To be conservative we assume that there is no liquidityprovision premium involved with reversal trading.

We asked the researchers of Nomura to provide us with aggregated data in the form of average trading costs for decile portfolios of S\&P1500 stocks sorted on their dollar volumes in each quarter during the period January 1990 to December 2009. ${ }^{3}$ Trading cost estimates for an individual stock can now be derived using the stock's volume rank at a particular point in time. An attractive feature of this approach is that it only requires readilyavailable volume data, and not proprietary intraday data. The trading cost schemes we publish in this study also enable other researchers to employ the Nomura trading cost estimates in their studies. We also asked them to assume that the trades are closed within one day and the trade size is one million USD per stock by the end of 2009. The trade size is deflated back in time with 10 percent per annum. The assumption of such a large trade size ensures that any effects we document can be exploited by a sizable strategy. For example, a strategy that is long-short in the 20 percent losers and winners of the largest 1,500 U.S. stocks and trades one million USD per stock employs a capital of USD 300 million by the end of 2009. We use the same trade sizes when using the Keim and Madhavan (1997) model to estimate trading costs.

Table 1 presents an overview of the trading cost estimates we received from Nomura for S\&P1500 stocks and also lists the estimates for our sample of the 1,500 largest U.S. stocks resulting from the Keim and Madhavan (1997) model.

\footnotetext{
${ }^{3}$ Because the S\&P1500 Index started in 1995, we asked the researchers of Nomura to backfill their series of trading cost estimates using the 1,500 largest stocks that are constituents of the Russell Index over the period January 1990 to December 1994.
} 


\section{[INSERT TABLE 1 ABOUT HERE]}

The table presents the average single-trip costs of buy and sell transactions in basis points for each year in our sample for decile portfolios of stocks sorted on their three-month median dollar trading volume. The shaded areas in the table mark the periods over which the employed transaction cost models are calibrated.

Panel A of Table 1 reports the cost estimates resulting from the Keim and Madhavan (1997) model. The cost estimates for our sample of stocks during the period 1991 to 1993 seem to be close to the estimates reported by Keim and Madhavan for the median stock (see Table 3 of their paper). However, there are also a few notable observations. We find negative cost estimates for the most liquid stocks with the largest trading volumes. The number of stocks with negative trading cost estimates also increases over time. In fact, the Keim and Madhavan model yields negative cost estimates for almost half of the stocks in our sample during 2007. Panel B of Table 1 reports the trading cost estimates that were provided to us by Nomura for S\&P1500 stocks. Interestingly, Nomura's cost estimates appear not only to be higher for the most liquid stocks with the highest trading volumes, but also for the least liquid stocks with the lowest trading volumes. For these stocks the cost estimates of Nomura can be up to six times higher than those resulting from the Keim and Madhavan model.

\section{[INSERT TABLE 2 ABOUT HERE]}

Once we focus on the 500 largest stocks in our sample, the differences between the trading cost estimates resulting from the Keim and Madhavan (1997) model and the Nomura model become even more extreme. Panel A of 
Table 2 reports the cost estimates resulting from the Keim and Madhavan model and Panel B the cost estimates that were provided to us by Nomura. We immediately observe that the cost estimates resulting from the Keim and Madhaven model for our sample of large cap stocks are very low and even negative in a lot of cases. In fact, for a large number of years in our sample, trading cost estimates are negative for basically all stocks. In addition, for all deciles, Nomura's cost estimates are substantially higher than the estimates resulting from the Keim and Madhavan model. Based on the Keim and Madhavan model, the average single-trip transaction costs for the 10 percent most expensive stocks to trade are 4 basis points. This figure is substantially lower than the 6 basis points trading costs that result from the Nomura model for the 10 percent cheapest stocks.

We offer the following explanations for these notable differences. First, the differences may be caused by the fact that the model of Nomura imposes a quadratic relation between trading volume and transaction costs while the Keim and Madhaven model imposes a logarithmic relation. While the economic intuition behind both approaches is that they try to mimic the shape of the limit order book that is deep in the front (at the best bid/offer price) and gets increasingly shallower as prices move away from the current price by imposing a convex relation between cost and volume [see, e.g., Roşu (2009)], an attractive feature of the quadratic relation over the logarithmic relation is that cost estimates cannot become negative for the most liquid stocks. When a logarithmic relation is imposed trading cost estimates can become negative. Second, the Keim and Madhavan model uses a constant negative coefficient for market capitalization. Because the average market capitalization increased 
significantly in our sample, cost estimates become lower over time. It should be stressed here that we did not apply scaling techniques on the coefficient estimates in the Keim and Madhavan model as is typically done in this stream of literature to inflate trading costs back in time [see, e.g., Gutierrez and Kelley (2008) and Avramov, Chordia, and Goyal (2006)]. If we would have applied these scaling techniques, the resulting cost estimates would be even lower. The Nomura model can adjust to changing market conditions in our sample because it is periodically recalibrated.

The observation that trading cost estimates resulting from the Keim and Madhavan (1997) model are substantially lower than the Nomura cost estimates (and even negative in many cases) makes us believe that the trading cost estimates resulting from the Keim and Madhavan model should be interpreted with caution in some of our analyses. Of course, it should be acknowledged that the Keim and Madhavan model was originally developed to describe the in-sample relation between trading costs and stock characteristics, and not to predict stocks' out-of-sample trading costs for evaluating trading strategies. Imposing a quadratic instead of a logarithmic relation between market capitalization and trading costs would probably not increase the in-sample explanatory power of the model. The Keim and Madhavan model is therefore probably optimally specified for the purpose it was originally developed for.

An additional attractive feature of the trading cost model we obtained from Nomura Securities is that it has also been calibrated using European trade data which enables us to investigate trading costs and reversal profits in these markets. To our best knowledge, this study is the first to provide a 
comprehensive overview of trading costs and to investigate trading cost impact on reversal profits in European equity markets. The lower liquidity of the European markets makes us expect that trading costs in Europe are higher than in the U.S. For comparison, we list the trading costs estimates we obtained from Nomura Securities for the largest 1,000 and 600 European stocks in Table 3. We asked the researchers of Nomura to use the same settings to compute trading costs in Europe as they used to compute trading costs in the U.S.

\section{[INSERT TABLE 3 ABOUT HERE]}

When we compare the trading costs estimates for the 1,500 largest U.S. stocks to those for the 1,000 largest European stocks in Panel A of Table 3, it appears that trading costs are indeed higher in Europe. For example, the trading costs of the 10 percent least liquid stocks are 76 basis points for European stocks, while the costs are 64 basis points for U.S. stocks. The differences become larger when we move to the more liquid segment of the market. For the 10 percent most liquid stocks, trading costs are even three times higher in Europe compared to the U.S. When we consider trading cost estimates for the 600 largest European stocks in Panel B of Table 3, we observe a very similar pattern in the sense that the most liquid U.S. stocks are significantly less expensive to trade.

\section{MAIN EMPIRICAL RESULTS}

\subsection{Reversal profits across different market cap segments}

In our first analysis we evaluate reversal profits for the 1,500, 500, and 100 largest U.S. stocks. Our hypothesis is that the reported impact of trading costs 
on reversal profits can largely be attributed to excessively trading in small cap stocks and that limiting the stock universe to large cap stocks significantly reduces trading costs.

Reversal portfolios are constructed by daily sorting all available stocks into mutually exclusive quintile portfolios based on their past-week returns (i.e., five trading days). We assign equal weights to the stocks in each quintile. The reversal strategy is long (short) in the 20 percent of stocks with the lowest (highest) returns over the past week. To control for the bid-ask bounces, we skip one day after each ranking before we construct portfolios. Portfolios are rebalanced at a daily frequency. We compute the gross and net returns of the long portfolio, the short portfolio, and the long-short portfolio in excess of the equally-weighted return of all stocks in the cross-section. In addition, we compute the long-short portfolios' turnover per week. We compute net returns for each stock at each point in time by taking the trading cost estimates listed in Tables 1 and 2. We impose that the minimum trading cost estimates resulting from the Keim and Madhavan model are zero to be conservative.

\section{[INSERT TABLE 4 ABOUT HERE]}

We first consider the results for a standard reversal strategy using the 1,500 largest U.S. stocks in Panel A of Table 4. Consistent with most of the literature we find that this strategy yields extremely large gross returns. More specifically, a reversal investment strategy that is long in the 20 percent stocks with the lowest one-week returns and short in the 20 percent with the highest returns earns a gross return of 61.7 basis points per week. 
However, at the same time the reversal strategy has an extremely high portfolio turnover of 677 percent per week. ${ }^{4}$ We find that the average holding period of a stock is less than three days. Once trading costs are taken into account the profitability of the reversal strategy completely diminishes. When we take Keim and Madhavan trading cost estimates, we document a net return of minus 66.1 basis points per week. And when we use the Nomura cost estimates, we even find a return of minus 103.7 basis points per week. These results are consistent with the findings of Avramov, Chordia and Goyal (2006).

One of the most notable observations in the previous section was that there is a highly non-linear relation between market capitalization/trading volume and trading costs such that the smallest and least liquid stocks are disproportionally expensive to trade. Especially since these stocks generally have the highest volatility and therefore have the greatest probability to end up in the extreme quantiles when stocks are ranked on past returns, a longshort reversal portfolio is typically invested in the stocks that are the most expensive to trade. While some studies report that stock anomalies are typically stronger among small cap stocks, one may wonder if the potentially higher returns of small cap stocks compensate for the higher trading costs of these stocks.

To investigate the impact of including small cap stocks, we consider the results for the 500 and 100 largest U.S. stocks in Panels B and C of Table 4, respectively. Interestingly, the reversal strategies for the largest 500 and 100 stocks earn slightly higher returns than the reversal strategy for the largest

\footnotetext{
${ }^{4}$ The maximum turnover of a long-short portfolio is 400 percent per day.
} 
1,500 stocks. Moreover, it appears that the impact of trading costs on the profitability of the strategy is much lower for our samples of large cap stocks. Given the large number of negative cost estimates we found using the Keim and Madhavan (1997) model for the largest 500 stocks, it is not surprising to see that the net return of the reversal strategy computed using these cost estimates are very close to the strategy's gross return since we impose minimum trading costs of zero. However, also when we use the trading cost estimates of Nomura, it appears that trading costs have a much smaller impact on reversal profits once small cap stocks are excluded. The net return of minus 3 basis points per week of the strategy for the 500 largest stocks indicates that trading costs consume roughly 75 basis points of the strategy's gross return. For the 100 largest stocks this figure is 53 basis points. For our sample of the 1,500 largest stocks trading impact is more than three times larger at 165 basis points.

The results from this analysis indicate that reversal profits are also observed among the largest stocks. In fact, reversal profits appear to be the highest among this group of stocks. Our finding that reversal strategies can yield a significant return of more than 30 basis points per week net of trading costs presents a serious challenge to standard rational asset pricing model and has important implications for the practical implementation of reversal investment strategies. The key lesson is that investors striving to earn superior returns by engaging in reversal trading are more likely to realize their objectives by trading in liquid stocks with relatively low transaction costs.

\subsection{Reducing reversal strategies' turnover by "smart" portfolio construction}


Another important reason why trading costs have such a large impact on reversal profits has to do with the way the reversal portfolios are typically constructed. Reversal portfolios are constructed by taking a long position in losers and a short position in winners. Then, at a pre-specified interval the portfolio is rebalanced and stocks that are no longer losers are sold and replaced by newly bottom-ranked stocks. And vice versa, stocks that are no longer winners are bought back and replaced by newly top-ranked stocks. While this portfolio construction approach is standard in the academic literature to investigate stock market anomalies, it is suboptimal when a reallive investment strategy is evaluated and trading costs are taken into account. Namely, replacing stocks that are no longer losers (winners) by newly bottom (top)-ranked stocks only increases the profitability of reversal strategies if the difference in expected return between the stocks is larger than the costs associated with the transactions.

In many cases, however, the costs of the rebalances will be larger than the incremental return that is earned by the stock replacements. For example, for our universe of the 1,500 largest stocks we found that past loser stocks on average earn a gross excess return of roughly 6 basis points over the subsequent day while stocks in the next quintile earn 1 basis point. On average, loser (winner) stocks remain ranked in the top (bottom) quintile for a period of three days. Consequently, replacing a stock that moved from the top quintile to the second quintile only increases the profitability of the reversal strategy if the costs of the buy and sell transactions are less than $15[=(6-1)$ * 3 ] basis points together. When we consider the trading cost estimates in Tables 1 and 2, however, we see that single-trip costs are larger than 7.5 
basis points in many cases. Therefore a portfolio construction approach that directly sells (buys back) stocks that are no longer losers (winners) is likely to generate excessive turnover and unnecessarily high transaction costs.

A naive approach to cope with this problem would be to lower the rebalancing frequency. However, with this approach one runs the risk to hold stocks that have already reverted. Namely, a loser (winner) stock at a specific point in time might rank among the winner (loser) stocks within the interval at which the portfolio is rebalanced and might therefore have a negative (positive) expected return. In fact, the portfolio weights of loser stocks that have reverted become larger and thereby exacerbate this effect.

We propose a slightly more sophisticated approach that waits to sell (buy back) stocks until they are ranked among the 50 percent of winner (loser) stocks ranked on past return. These stocks are then replaced by the stocks with the lowest (highest) past-week return at that time and not yet included in the portfolio. As a consequence, this "smart" approach has a substantially lower turnover than the standard approach to construct long-short reversal portfolios. It is important to note that our "smart" approach holds the same number of stocks in the portfolio as the standard approach, but that the holding period with the "smart" approach is flexible for each stock with a minimum of one day and a maximum of theoretically infinity.

We now use the slightly more sophisticated portfolio construction approach outlined above to evaluate reversal profits for our samples of the $1,500,500$, and 100 largest U.S. stocks. Our hypothesis is that trading costs can significantly be reduced without giving up too much of the gross reversal 
profits when our slightly more sophisticated portfolio construction algorithm is applied.

\section{[INSERT TABLE 5 ABOUT HERE]}

We first consider the results for our sample of the 1,500 largest stocks in Panel A of Table 5. Indeed, the "smart" portfolio construction approach appears to successfully reduce turnover and thereby the impact of trading costs on reversal profits. While the turnover of the standard reversal strategy for the 1,500 largest stocks is 677 percent per week, this figure is 325 percent for the "smart" approach. We find that the effective holding period of a stock on average is approximately six days for this strategy. And while trading costs, estimated using the Keim and Madhavan (1997) model, consume 128 basis points of reversal gross returns of the standard reversal strategy, this figure is 61 basis points for the "smart" approach. We find a similar impact when we use the Nomura trading cost estimates. While trading costs consume 165 basis points for the standard reversal strategy, this figure is 77 basis points for the "smart" approach. All in all, it appears that using a slightly more sophisticated portfolio construction approach when engaging in short-term reversal strategies can have a significant impact on trading costs.

Next, we consider the results for the 500 and 100 largest U.S. stocks in Panels B and C of Table 5. Also for these samples we see that the "smart" portfolio construction approach appears to successfully reduce turnover. More specifically, while the standard reversal strategies have turnovers of 688 and 711 percent per week, these figures are 326 and 337 percent for the "smart" reversal strategies applied on the 500 and 100 largest stocks, respectively. Interestingly, the gross returns of the "smart" strategies are only marginally 
lower than the returns we observed earlier for the standard reversal strategies. When net returns are computed using the Nomura model we find that trading costs now consume only 34 basis points of the strategy's gross return for the 500 largest U.S. stocks. This figure is 75 basis points for the standard reversal strategy. We observe a similar reduction for our sample of the 100 largest U.S. stocks. The resulting reversal profits range between 30 and 50 basis points per week and are highly significant from both a statistical as an economical point of view.

\subsection{Reversal profits in European markets}

Proceeding further we evaluate reversal profits in European stocks markets. Only a small number of studies have investigated short-term reversal strategies in non-US equity markets. Chang, Liu and Ni (1995) find abnormal profits of short-term contrarian strategies in the Japanese stock market. Schiereck, DeBondt, and Weber (1999) and Hameed and Ting (2000) find the same in the German and Malaysian stock markets, respectively. And Griffin, Kelly, and Nardari (2010) investigate reversal profits in 56 developed and emerging countries.

Because European markets are less liquid than the U.S. market we expect the impact of trading costs on reversal profits to be larger in Europe. Using the methodology outlined in the previous section, we construct quintile portfolios for the 1,000, 600 and 100 largest European stocks to compute the returns of long-short reversal portfolios. Additionally, we apply the "smart" portfolio construction for these stock samples. For all reversal strategies we compute gross returns, and returns net of trading costs using the estimates 
from the Nomura model listed in Table 3. The results of this analysis are presented in Table 6.

\section{[INSERT TABLE 6 ABOUT HERE]}

It appears that gross reversal profits are also very large in Europe and in the same order of magnitude as in the U.S. However, as we expected, the impact of trading costs appears to be larger in Europe. For our universes of the 1,000 and 600 largest European stocks we do not find positive returns net of trading costs. Only when we exclusively focus on the 100 largest stocks and apply the "smart" portfolio construction, we document significantly positive net reversal profits up to 20 basis points per week.

All in all, the European results exhibit the same features as our U.S. results: once we move more towards the large cap segment of the market and limit turnover by "smart" portfolio construction, reversal strategies yield significant returns net of trading costs. At the same time, trading costs have a larger impact on reversal profits in Europe than in the U.S.

\section{FOLLOW-UP EMPIRICAL ANALYSES}

\subsection{Weekly rebalancing}

In our first follow-up empirical analysis we evaluate a naive portfolio construction approach that reduces the turnover of reversal strategies by decreasing the rebalancing frequency to five days. All the other settings are exactly the same as with the standard approach. As mentioned earlier, the

main disadvantage of this approach compared to the "smart" portfolio construction approach described in the previous section is that one runs the risk to hold stocks that have already reverted. We evaluate this portfolio 
construction approach for our samples of the largest 1,500, 500 and 100 largest U.S. stocks. The results are in Table 7.

\section{[INSERT TABLE 7 ABOUT HERE]}

It appears that using a five-day rebalancing frequency indeed substantially lowers portfolio turnover. For example, the turnover of the standard reversal strategy for the 1,500 largest stocks is 677 percent per week. This figure is 306 percent per week using a five-day rebalancing frequency. Also for our samples of the largest 500 and 100 stocks, the turnover of reversal strategies that use a five-day rebalancing frequency is less than half of the turnover of strategies that rebalance at a daily frequency. As a consequence, the impact of trading costs is substantially lower for these strategies. Nonetheless, the net returns of the weekly reversal strategy for the 1,500 largest stocks are significantly negative because the gross returns of the strategy are also much lower than for the daily strategy. While the daily strategy yields a gross return of 62 basis points per week, the weekly strategy yields only 41 basis points. For our samples of the largest 500 and 100 stocks we observe similar effects: trading costs become substantially lower when the rebalancing frequency is decreased to five days, but so do gross returns. The effects seem to offset each other such that net reversal profits remain in the same order of magnitude.

\subsection{Subperiod analyses}

We continue our empirical analysis by performing two subperiod analyses. First, we investigate reversal profits over the most recent decade in our sample (i.e., January 2000 to December 2009). We conjecture that it might 
well be the case that the decimalization of the quotation systems and the increase in stock trading volumes have affected the profitability of reversal profits. Additionally, the Adaptive Market Hypothesis of Lo (2004) states that the public dissemination of an anomaly may affect its profitability. We conjecture that it could well be the case that increased investment activities by professional investors such as hedge funds have arbitraged away a large portion of the anomalous profits of reversal strategies after publications on the reversal effect in the 1990s. The results of this analysis are presented in Panels A, B and C in Table 8.

\section{[INSERT TABLE 8 ABOUT HERE]}

It appears that the net profitability of our "smart" reversal investment strategy is quite constant over our sample period. For the 1,500 largest stocks, the "smart" reversal strategy yields a negative net return of minus 27.9 basis points per week in the most recent decade. For our sample of the 500 largest stocks, the net return decreased from 30.5 to 22.1 basis points per week. And for our sample of the largest 100 stocks, the net return slightly increased from 53.1 basis points to 59.0 basis points per week.

In our second subperiod analysis we evaluate reversal profits when leaving out the dotcom bubble years (i.e., January 1999 to December 2001) and the credit crisis (i.e., January 2008 to December 2009) from our sample. Our concern is that the trading cost models we employ underestimate costs during crises periods and reversal profits are exacerbated. The results of this analysis are reported in Panels D, E, and F of Table 8. Observing net reversal profits of minus $17.8,23.2$, and 34.8 basis points per week for the $1,500,500$, 
and 100 largest U.S. stocks, respectively, we conclude that the reversal profits are constant over time and also highly profitable during non-crises periods.

\section{3 "Smart" portfolio construction using alternative trade rules}

Next we examine the sensitivity of our findings to alternate portfolio construction rule choices. More specifically, we evaluate reversal profits for the 500 largest U.S. stocks that sell (buy back) stocks once their rank on pastweek return is above (below) the 30th (70th) percentile; the 40th (60th) percentile; the 60th (40th) percentile; the 70th (30th) percentile; and the 80th (20th) percentile.

\section{[INSERT TABLE 9 ABOUT HERE]}

The results in Panel A of Table 9 point out that reducing portfolio turnover has a large impact on net reversal profits. Once we require loser (winner) stocks with a rank above (below) the 30th (70th) percentile to be sold (bought back), net reversal profits become highly significant at 20.1 basis points per week. This compares to minus 3 basis points per week for the standard reversal strategy (see Table 4). While gross returns become somewhat lower when turnover is reduced, the impact of trading costs on performance becomes substantially smaller at the same time. The optimum in terms of net return is reached using a trade rule that sells (buys back) stocks once their rank on past-week return is above (below) the 70th (30th) percentile. Interestingly, it appears that reversal profits are both statistically and economically highly significant for all trade rules, ranging from 20.1 to 35.3 basis points per week. We can therefore safely conclude that our findings are robust to our choice of trade rule. 


\subsection{Fama-French regressions}

To investigate to which extent reversal profits can be attributed to exposures to common risk factors we regress gross and net returns of the "smart" longshort reversal portfolios for the largest 1,500, 500 and 100 U.S. stocks on the Fama-French risk factors (French, 2010) for market, size and value [see, e.g., Fama and French $(1993,1995,1996)]$ :

$$
r_{i, t}=a+b_{1} S R M R F_{t}+b_{2} S M B_{t}+b_{3} H M L_{t}+\varepsilon_{i, i},
$$

where $r_{i, t}$ is the return on reversal strategy $i$ in month $t, R M R F_{t}, S M B_{t}$ and $H M L_{t}$ are the returns on factor-mimicking portfolios for the market, size and value in month $t$, respectively, $a, b_{1}, b_{2}$ and $b_{3}$ are parameters to be estimated, and $\varepsilon_{i, t}$ is the residual return of strategy $i$ in month $t$. The coefficient estimates and adjusted R-squared values from these regressions are listed in Table 10.

\section{[INSERT TABLE 10 ABOUT HERE]}

Panel A presents the results for the 1,500 largest U.S. stocks, Panel B presents the results for the 500 largest U.S. stocks, and Panel C presents the results for the 100 largest U.S. stocks. In all cases the explanatory power of the Fama-French risk factors is very small. The highest adjusted R-squared value we observe is 5 percent. We conclude that reversal profits are unrelated to exposures to common risk factors.

\section{IMPLICATIONS FOR EXPLANATIONS FOR REVERSAL EFFECTS}


Our findings have important implications for explanations that have been put forward in the literature to explain the reversal anomaly. Short-term stock reversals are sometimes regarded as evidence that the market lacks sufficient liquidity to offset price effects caused by unexpected buying and selling pressure and that market makers set prices in part to control their inventories. Grossman and Miller (1988) and Jegadeesh and Titman (1995b) argue that the reversals are induced by inventory imbalances by market makers and the contrarian profits are a compensation for bearing inventory risks. Related to this stream of literature, Madhavan and Smidt (1993), Hasbrouck and Sofianos (1993), Hansch, Naik, and Viswanathan (1998), and Hendershott and Seasholes (2006) find that prices quoted by dealers are inversely related to their inventory supporting the notion that dealers actively manage their inventories. This liquidity explanation projects that reversals should have become smaller over time since market liquidity dramatically increased. It also predicts that reversals are stronger for small cap stocks than large cap stocks that typically have lower turnover. In fact, under the liquidity hypothesis reversals may even not be present among large cap stocks at all. However, our findings that net reversal profits are large and positive for the 500 and 100 largest U.S. stocks and did not diminish over the second decade in our sample rules out this explanation.

Another explanation for reversal effects that has been put forward in the literature is from Lo and MacKinlay (1990) and Boudoukh, Richardson, and Whitelaw (1994) who note that nonsynchronous trading contributes to contrarian profits. This explanation assumes information diffuses gradually in financial markets and that large cap stocks react more quickly to information 
than small cap stocks that are covered by fewer analysts. As a consequence of this, the returns of large cap stocks might lead the returns of small cap stocks. However, our finding that reversal profits are smaller for the 1,500 largest U.S. stocks than for the 500 and 100 largest stocks is inconsistent with this explanation since nonsynchronous trading predicts a size-related leadlag-effect in stock returns and higher reversal profits among small cap stocks.

The only explanation that has been put forward in the literature whose projections are not inconsistent with our findings is the behavioural explanation that market prices tend to overreact to information in the short run [see, e.g., Jegadeesh and Titman (1995a)]. It should be stressed that our study does not provide any direct evidence supporting this behavioural hypothesis. Of course, it is not our goal to explain the reversal effect in this study; our main point is to show that reversal profits are present after trading costs. Nonetheless, we believe that our results help to better understand the reversal anomaly since it rules out several competing explanations that have been put forward in the literature.

\section{SUMMARY AND CONCLUDING COMMENTS}

This paper shows that the finding that trading costs prevent profitable execution of reversal investment strategies can largely be attributed to excessively trading in small cap stocks. Excluding small cap stocks and applying a slightly more sophisticated portfolios construction approach to reduce turnover when engaging in reversal trading has a tremendous impact on the returns that reversal investment strategies deliver net of transaction costs. Our finding that reversal strategies generate 30 to 50 basis points per 
week net of transaction costs poses a serious challenge to standard rational asset pricing models and has important implications for the practical implementation of reversal investment strategies. Our results also have important implications for several explanations that have been put forward in the literature to explain the reversal anomaly.

Another important issue that came to light in this study is that trading cost estimates of the Keim and Madhavan (1997) model that are typically used in this stream of literature to evaluate the profitability of trading strategies net of transaction costs should be interpreted with caution in some cases. More specifically, it seems that cost estimates of this model are systematically biased downwards and can even become negative. The comprehensive overviews presented in this study on trading costs estimates for S\&P1500, S\&P500 stocks and the largest 1,000 and 600 European stocks resulting from the proprietary transaction cost model of Nomura Securities, one of world's largest stock brokers, provides new opportunities for future research to reevaluate the profitability of investment strategies based on well-documented anomalies such as the value and the momentum effects. 


\section{APPENDIX}

This appendix describes the Keim and Madhavan (1997) and the Nomura models we use throughout this study to estimate trading costs.

\section{A. Keim and Madhavan (1997) model}

As Avramov, Chordia and Goyal (2006) do in their study, we employ the regression results of Keim and Madhavan to estimate the transaction costs involved with reversal investment strategies. Using the results in Table 5 of Keim and Madhavan we obtain our estimates of buyer and seller trading costs:

(2) $\hat{C}^{B u y}{ }_{i}=0.767+0.336 D^{\text {NASDAQ }}+0.092 \frac{1}{\text { mcap }_{i}}$ Trsize $_{i}-0.084 \log$ mcap $_{i}+13.807\left(\frac{1}{P_{i}}\right)$

(3) $\hat{C}^{\text {Sell }}{ }_{i}=0.505+0.058 D^{\text {NASDAQ }}+0.214 \frac{1}{\text { mcap }_{i}}$ Trsize $_{i}-0.059 \log$ mcap $_{i}+6.537\left(\frac{1}{P_{i}}\right)$

where $\hat{C}^{\text {Buy }}{ }_{i}$ and $\hat{C}^{\text {sell }}{ }_{i}$ are the estimated total trading costs for stock $i$ in percent for either a buyer-initiated or seller-initiated order, respectively. $D^{N A S D A Q}$ is equal to one if stock $i$ is a NASDAQ-traded stock and zero if stock $i$ is traded on NYSE or AMEX, mcap is the market value outstanding of stock $i$, Trsize $_{i}$ is the trade size of stock $i$, and $P_{i}$ is the price per share of stock $i$. For our long portfolios we use $\hat{C}^{B u y}{ }_{i}$ to open the positions in the component stocks and $\hat{C}^{\text {Sell }}{ }_{i}$ to close the positions, vice versa for the short portfolios. Keim and Madhavan estimate the trading costs for 21 institutions from January 1991 through March 1993 using 62,333 trades. 


\section{B. Nomura model for trading costs}

The variables that are assumed to determine trading costs in the model developed by Nomura are spread, trade size, volume and volatility:

(4) $\hat{C}_{i}=a+b_{1}$ spread $_{i}+b_{2} \frac{1}{\text { volume }_{i}^{2}}$ Trsize $_{i}+b_{3}$ volatility $_{i}+\varepsilon_{i}$

where spread $_{i}$ is the average bid-ask spread of stock $i$ over the trading day, volume $_{i}$ is the total executed volume for stock $i$ over the trading day, Trsize $_{i}$ is the trade size of stock $i$, and volatility $y_{i}$ the intra-day return volatility of stock $i$ over the trading day. The Nomura trading cost model is calibrated in every quarter over the period 1995 to 2009. For each calibration, actual order flows in the previous 12 months for approximately 500,000 executed trades per time are used from the trading platform formerly owned by Lehman Brothers. The calibration is done per region and exchange to take differing transaction costs across exchanges into account.

The model developed by Nomura estimates transaction costs by decomposing them into three components. The first component is the instantaneous impact due to crossing the bid-ask spread. The second component is the permanent impact which is the change in market equilibrium price due to executing a trade. Finally, the third component is the temporary impact which refers to a temporary movement of price away from equilibrium price because of short-term imbalances in supply and demand. The model does not take opportunity costs into account that result from unfilled trades. 


\section{REFERENCES}

Amihud, Y., 2002, "Illiquidity and Stock Returns: Cross-section and Timeseries Effects" Journal of Financial Markets, 5, 31-56.

Avramov, D., T. Chordia, and A. Goyal, 2006, "Liquidity and autocorrelations in individual stock returns", Journal of Finance, 61, 2365-2394.

Ball, R., S.P. Kothari, and C.E. Wasley, 1995, "Can we implement research on stock trading rules?", Journal of Portfolio Management, 21, 54-63.

Boudoukh, J., M.P. Richardson, and R.F. Whitelaw, 1994, "Tale of three schools: Insights on autocorrelations of short-horizon stock returns", Review of Financial Studies, 7, 539-573.

Chan, W.S., 2003, "Stock Price Reaction to News and No-News: Drift and Reversal after Headlines", Journal of Financial Economics, 70, 223-260.

Chang, R.P., D.W. McLeavey, and S.G. Rhee, 1995, "Short-term abnormal returns of the contrarian strategy in the Japanese stock market", Journal of Business Finance and Accounting, 22, 1035-1048.

Chordia, T., A. Goyal, G. Sadka, R. Sadka, and L. Shivakumar, 2009, "Liquidity and the Post-Earnings-Announcement Drift", Financial Analysts Journal, 65, 18-32.

Conrad, J.S., A. Hameed, and C. Niden, 1994, "Volume and autocovariances in short-horizon individual security returns", Journal of Finance, 49, 13051329.

Fama, E.F., 1965, "The Behavior of Stock Market Prices", Journal of Business, 38, 34-105.

Fama, E.F., and K.R. French, 1993, "Common risk factors in the returns on stocks and bonds," Journal of Financial Economics, 33, 3-56. 
Fama, E.F., and K.R. French, 1995, "Size and book-to-market factors in earnings and returns," Journal of Finance, 50, 131-155.

Fama, E.F., and K.R. French, 1996, "Multifactor explanations of asset pricing anomalies," Journal of Finance, 1, 55-84.

French, K.R., Fama-French Factors, 2010, Retrieved July 2010 from http://mba.tuck.dartmouth.edu/pages/faculty/ken.french/data_library.html

Gajewskia, J, and C. Gresse, 2007, "Centralised Order Books versus Hybrid Order books: A Paired Comparison of Trading Costs on NSC (Euronext Paris) and SETS (London Stock Exchange)", Journal of Banking and Finance, 31, 2906-2924.

Gutierrez Jr., R.C., and E.K. Kelley, 2008, "The Long-Lasting Momentum in Weekly Returns", Journal of Finance, 63, 415-447.

Griffin, J.M., P.J. Kelly, and F. Nardari 2010, "Are Emerging Markets More Profitable? Implications for Comparing Weak and Semi-Strong Form Efficiency", Review of Financial Studies, forthcoming.

Grossman, S., and M. Miller, 1988, "Liquidity and Market Structure", Journal of Finance, 43, 617-633.

Hameed, A., S. Ting, 2000, "Trading volume and short-horizon contrarian profits: Evidence from Malaysian stock market", Pacific-Basin Finance Journal, 8, 67-84.

Hansch, O., N.Y. Naik, and S. Viswanathan, 1998, "Do inventories matter in dealership markets? Evidence from the London Stock Exchange", Journal of Finance, 53, 1623-1656. 
Hasbrouck, J., and G. Sofianos, 1993, "The trades of market makers: An empirical analysis of NYSE specialists", Journal of Finance, 48, 1565-1593.

Hendershott, T., and M.S. Seasholes, 2006, "Specialist inventories and stock prices", American Economic Review Papers and Proceedings, 97, 210-214.

Kang, J., M.H. Liu, S.X. Ni, 2002, "Contrarian and momentum strategies in the China stock market: 1993-2000", Pacific-Basin Finance Journal, 10, 243-265

Jegadeesh, N., 1990, "Evidence of predictable behavior of security returns", Journal of Finance, 45, 881-898.

Jegadeesh, N. and S. Titman, 1995a, "Overreaction, Delayed Reaction, and Contrarian Profits", Review of Financial Studies, 8, 973-993.

Jegadeesh, N. and S. Titman, 1995b, "Short-Horizon Return Reversals and the Bid-Ask Spread", Journal of Financial Intermediation, 4, 116-132.

Kaul, G., and M. Nimalendran, 1990, "Price reversals: Bid-ask errors or market overreaction?", Journal of Financial Economics, 28, 67-93.

Keim, D.B., and A. Madhavan, 1997, "Transaction Costs and Investment Style: An Inter-Exchange Analysis of Institutional Equity Trades", Journal of Financial Economics, 46, 265-292.

Korajczyk, R., and R. Sadka, 2004, "Are Momentum Profits Robust to Trading Costs?", Journal of Finance, 59, 1039-1082.

Lehmann, B., 1990, "Fads, martingales, and market efficiency", Quarterly Journal of Economics, 105, 1-28.

Lesmond, D.A., M. J. Schill, and C. Zhou, 2004, "The Illusory Nature of Momentum Profits", Journal of Financial Economics, 71, 349-380. 
Lo, A.W., 2004, "The adaptive markets hypothesis: market efficiency from an evolutionary perspective", Journal of Portfolio Management, 30, 15-29.

Lo, A.W., and A.C. MacKinlay, 1990, "When are Contrarian Profits Due to Stock Market Overreaction?", Review of Financial Studies, 3, 175-205.

Madhavan, A., and S. Smidt, 1993, "An analysis of changes in specialists inventories and quotations", Journal of Finance, 48, 1595-1628.

Rosenberg, B., K. Reid, and R. Lanstein, 1985, "Persuasive Evidence of Market Inefficiency", Journal of Portfolio Management, 11, 9-17.

Roşu, I., 2009, "A Dynamic Model of the Limit Order Book", Review of Financial Studies, 22, 4601-4641.

Schiereck, D., W. DeBondt, M. Weber, 1999, "Contrarian and momentum strategies in Germany", Financial Analysts Journal, 55, 104-116.

Subrahmanyam, A., 2005, "Distinguishing Between Rationales for ShortHorizon Predictability of Stock Returns", Financial Review, 40, 11-35.

Tse, Y., and E. Devos, 2004, "Trading Costs, Investor Recognition and Market Response: An Analysis of Firms that move from the Amex (Nasdaq) to Nasdaq (Amex) ", Journal of Banking and Finance, 28, 63-83. 
TABLE 1. Transaction cost estimates for the 1,500 largest U.S. stocks.

Table 1 presents an overview of the single-trip transaction cost estimates in basis points for volume deciles of our sample of the 1,500 largest U.S. stocks resulting from the Keim and Madhavan model (Panel A) and the estimates for volume deciles of S\&P1500 stocks we received from Nomura Securities (Panel B). The shaded areas mark the periods over which the employed transaction cost models are calibrated. Volume deciles are based on stocks' three-month median trading volumes. It is assumed that the trades are closed within one day and the trade size is one million per stock by the end of 2009 . The trade size is deflated back in time with 10 percent per annum.

\begin{tabular}{|c|c|c|c|c|c|c|c|c|c|c|c|c|c|c|c|c|c|c|c|c|c|}
\hline $\begin{array}{l}\text { Volume } \\
\text { Decile }\end{array}$ & ஓ & চ্ & ๙ั & ঙ্ণ & 奇 & ஜூ & ஜ & ڤ્' & $\stackrel{\infty}{\stackrel{\circ}{\circ}}$ & ஓ & 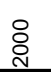 & ¿্ণ & ণิ & ర్ల & ষ্ণ & 옹 & 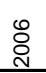 & 仓ิ & $\stackrel{\infty}{\circ}$ & : & $\begin{array}{l}\frac{0}{\pi} \\
\frac{\pi}{ \pm} \\
\frac{1}{2}\end{array}$ \\
\hline \multicolumn{22}{|c|}{ Panel A. Keim-Madhaven average buy and sell } \\
\hline D1 (bottom) & 71 & 78 & 47 & 28 & 29 & 27 & 21 & 12 & 13 & 18 & 21 & 26 & 30 & 29 & 13 & 12 & 10 & 11 & 38 & 63 & 30 \\
\hline D2 & 82 & 74 & 53 & 32 & 33 & 30 & 20 & 10 & 14 & 20 & 27 & 29 & 38 & 36 & 15 & 13 & 9 & 8 & 37 & 66 & 32 \\
\hline D3 & 64 & 72 & 51 & 32 & 30 & 25 & 18 & 11 & 15 & 19 & 24 & 24 & 39 & 35 & 19 & 10 & 7 & 7 & 40 & 61 & 30 \\
\hline D4 & 56 & 53 & 38 & 30 & 32 & 25 & 15 & 12 & 14 & 18 & 21 & 29 & 42 & 32 & 19 & 15 & 6 & 8 & 34 & 58 & 28 \\
\hline D5 & 48 & 39 & 32 & 30 & 25 & 22 & 15 & 9 & 11 & 17 & 15 & 27 & 43 & 38 & 15 & 16 & 6 & 4 & 24 & 37 & 24 \\
\hline D6 & 38 & 29 & 23 & 22 & 20 & 14 & 10 & 8 & 8 & 11 & 15 & 23 & 41 & 26 & 14 & 11 & 6 & 1 & 16 & 34 & 18 \\
\hline D7 & 24 & 20 & 18 & 13 & 14 & 8 & 6 & 1 & 4 & 5 & 6 & 15 & 26 & 22 & 8 & 2 & 2 & -6 & 15 & 28 & 11 \\
\hline D8 & 16 & 11 & 9 & 8 & 4 & 4 & 1 & -3 & -5 & -6 & 0 & 13 & 14 & 10 & 2 & -6 & -11 & -14 & 7 & 21 & 4 \\
\hline D9 & 0 & -3 & -5 & -5 & -2 & -6 & -6 & -11 & -12 & -13 & -10 & 0 & 3 & 0 & -9 & -17 & -16 & -21 & -5 & 8 & -7 \\
\hline D10 (top) & -20 & -20 & -19 & -19 & -17 & -19 & -22 & -26 & -28 & -31 & -25 & -14 & -5 & -11 & -17 & -25 & -26 & -31 & -21 & -15 & -20 \\
\hline \multicolumn{22}{|c|}{ Panel B. Nomura buy or sell } \\
\hline D1 (bottom) & 86 & 77 & 83 & 75 & 73 & 54 & 52 & 66 & 53 & 76 & 65 & 88 & 80 & 76 & 76 & 65 & 53 & 41 & 51 & 70 & 68 \\
\hline $\mathrm{D} 2$ & 72 & 60 & 60 & 55 & 51 & 34 & 27 & 35 & 31 & 65 & 67 & 61 & 56 & 50 & 41 & 30 & 24 & 20 & 25 & 50 & 46 \\
\hline D3 & 58 & 50 & 45 & 41 & 38 & 23 & 19 & 22 & 23 & 47 & 47 & 37 & 30 & 24 & 20 & 17 & 15 & 14 & 17 & 33 & 31 \\
\hline D4 & 48 & 41 & 36 & 30 & 30 & 17 & 12 & 18 & 18 & 30 & 28 & 23 & 20 & 17 & 14 & 13 & 12 & 11 & 13 & 23 & 23 \\
\hline D5 & 41 & 34 & 30 & 26 & 25 & 15 & 14 & 14 & 17 & 21 & 19 & 16 & 15 & 13 & 12 & 11 & 10 & 9 & 11 & 17 & 19 \\
\hline D6 & 33 & 26 & 22 & 21 & 20 & 13 & 13 & 12 & 14 & 16 & 14 & 13 & 12 & 11 & 10 & 9 & 9 & 8 & 9 & 14 & 15 \\
\hline D7 & 26 & 23 & 21 & 18 & 17 & 11 & 17 & 11 & 11 & 13 & 11 & 10 & 9 & 9 & 8 & 8 & 8 & 7 & 8 & 11 & 13 \\
\hline D8 & 22 & 20 & 18 & 16 & 14 & 10 & 17 & 13 & 10 & 11 & 9 & 8 & 8 & 8 & 7 & 7 & 6 & 6 & 6 & 9 & 11 \\
\hline D9 & 17 & 15 & 14 & 13 & 13 & 9 & 11 & 11 & 10 & 9 & 7 & 7 & 7 & 6 & 6 & 6 & 6 & 5 & 6 & 7 & 9 \\
\hline D10 (top) & 13 & 14 & 14 & 13 & 13 & 10 & 9 & 8 & 8 & 7 & 5 & 5 & 5 & 5 & 5 & 5 & 5 & 5 & 5 & 5 & 8 \\
\hline
\end{tabular}


TABLE 2. Transaction cost estimates for the $\mathbf{5 0 0}$ largest U.S. stocks.

Table 2 presents an overview of the single-trip transaction cost estimates in basis points for volume deciles of our sample of the 500 largest U.S. stocks resulting from the Keim and Madhavan model (Panel A) and the estimates for volume deciles of S\&P500 stocks we received from Nomura Securities (Panel B). The shaded areas mark the periods over which the employed transaction cost models are calibrated. Volume deciles are based on stocks' three-month median trading volumes. It is assumed that the trades are closed within one day and the trade size is one million USD per stock by the end of 2009. The trade size is deflated back in time with 10 percent per annum.

\begin{tabular}{|c|c|c|c|c|c|c|c|c|c|c|c|c|c|c|c|c|c|c|c|c|c|}
\hline $\begin{array}{l}\text { Volume } \\
\text { Decile }\end{array}$ & ஓ & S্ & ๙ু & ঙ্ণ & চ্ & 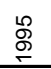 & ஜ & बे & $\stackrel{\infty}{\circ}$ & ஓ্ & 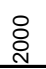 & 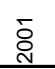 & ণิ & ஜ્ટ & ষ্ণ & $\stackrel{\text { L }}{\text { ¿ }}$ & 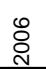 & ¿̊̀ & 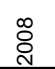 & : & $\sum_{\frac{\pi}{2}}^{\frac{\pi}{\alpha}}$ \\
\hline \multicolumn{22}{|c|}{ Panel A. Keim-Madhaven average buy and sell } \\
\hline D1 (bottom) & 14 & 6 & 2 & 1 & 8 & 8 & 2 & -4 & 0 & 6 & 9 & 8 & 4 & 3 & -4 & -9 & -11 & -16 & -5 & 51 & 4 \\
\hline D2 & 14 & 10 & 3 & 1 & 3 & 0 & -1 & -8 & -8 & -5 & -4 & -3 & 5 & 7 & -3 & -9 & -12 & -16 & -4 & 46 & 1 \\
\hline D3 & 12 & 6 & 5 & 1 & 1 & -2 & -8 & -11 & -10 & -8 & -6 & -3 & 3 & -1 & -8 & -13 & -16 & -19 & -2 & 40 & -2 \\
\hline D4 & 8 & 7 & 3 & 0 & 0 & -2 & -7 & -11 & -12 & -11 & -11 & -6 & 2 & -1 & -11 & -15 & -19 & -19 & -6 & 39 & -4 \\
\hline D5 & 9 & 5 & 1 & -2 & -2 & -3 & -10 & -12 & -14 & -15 & -12 & -10 & 0 & -1 & -11 & -16 & -21 & -21 & -10 & 28 & -6 \\
\hline D6 & 6 & 1 & -4 & -7 & -3 & -7 & -11 & -15 & -16 & -16 & -17 & -11 & 2 & -3 & -14 & -21 & -18 & -23 & -7 & 26 & -8 \\
\hline D7 & 1 & -5 & -6 & -8 & -5 & -10 & -12 & -17 & -17 & -16 & -20 & -8 & 1 & -2 & -15 & -16 & -18 & -22 & -11 & 15 & -10 \\
\hline D8 & -7 & -10 & -9 & -10 & -9 & -12 & -15 & -17 & -19 & -24 & -21 & -9 & 0 & 0 & -14 & -16 & -21 & -28 & -8 & 16 & -12 \\
\hline D9 & -12 & -10 & -13 & -15 & -14 & -17 & -21 & -25 & -27 & -30 & -29 & -16 & -9 & -12 & -14 & -24 & -22 & -27 & -17 & 2 & -18 \\
\hline D10 (top) & -24 & -25 & -27 & -24 & -24 & -27 & -29 & -34 & -38 & -39 & -38 & -19 & -4 & -22 & -27 & -30 & -32 & -34 & -24 & -16 & -27 \\
\hline \multicolumn{22}{|c|}{ Panel B. Nomura buy or sell } \\
\hline D1 (bottom) & 23 & 15 & 13 & 15 & 22 & 31 & 25 & 24 & 23 & 23 & 34 & 36 & 34 & 38 & 40 & 28 & 19 & 15 & 13 & 21 & 25 \\
\hline D2 & 12 & 11 & 10 & 12 & 16 & 22 & 13 & 14 & 16 & 27 & 26 & 20 & 17 & 17 & 14 & 11 & 10 & 9 & 10 & 14 & 15 \\
\hline D3 & 11 & 10 & 9 & 11 & 14 & 14 & 11 & 17 & 14 & 16 & 16 & 13 & 12 & 12 & 10 & 9 & 9 & 8 & 8 & 12 & 12 \\
\hline D4 & 10 & 9 & 9 & 11 & 12 & 12 & 12 & 12 & 12 & 13 & 12 & 11 & 10 & 10 & 9 & 8 & 8 & 7 & 7 & 11 & 10 \\
\hline D5 & 9 & 9 & 8 & 10 & 11 & 12 & 12 & 11 & 10 & 11 & 10 & 9 & 9 & 9 & 8 & 7 & 7 & 6 & 7 & 9 & 9 \\
\hline D6 & 8 & 8 & 8 & 9 & 10 & 13 & 12 & 11 & 10 & 10 & 9 & 8 & 8 & 8 & 7 & 7 & 6 & 6 & 6 & 9 & 9 \\
\hline D7 & 8 & 8 & 8 & 9 & 9 & 11 & 11 & 10 & 9 & 11 & 8 & 7 & 7 & 7 & 7 & 6 & 6 & 6 & 6 & 8 & 8 \\
\hline D8 & 8 & 8 & 7 & 8 & 9 & 11 & 11 & 10 & 10 & 9 & 7 & 6 & 7 & 7 & 6 & 6 & 6 & 5 & 6 & 7 & 8 \\
\hline D9 & 7 & 7 & 7 & 7 & 9 & 10 & 9 & 9 & 9 & 8 & 6 & 6 & 6 & 6 & 6 & 5 & 5 & 5 & 5 & 6 & 7 \\
\hline D10 (top) & 7 & 7 & 6 & 7 & 8 & 10 & 9 & 8 & 8 & 7 & 4 & 5 & 5 & 5 & 5 & 5 & 5 & 4 & 4 & 5 & 6 \\
\hline
\end{tabular}


TABLE 3. Transaction cost estimates for the 1,000 and 600 largest European stocks.

Table 3 presents an overview of the single-trip transaction cost estimates in basis points for volume deciles of our sample of the 1,000 (Panel A) and 600 (Panel B) largest European stocks resulting from the estimates for volume deciles we received from Nomura Securities. The shaded areas mark the periods over which the employed transaction cost models are calibrated. Volume deciles are based on stocks' three-month median trading volumes. It is assumed that the trades are closed within one day and the trade size is one million per stock by the end of 2009. The trade size is deflated back in time with 10 percent per annum.

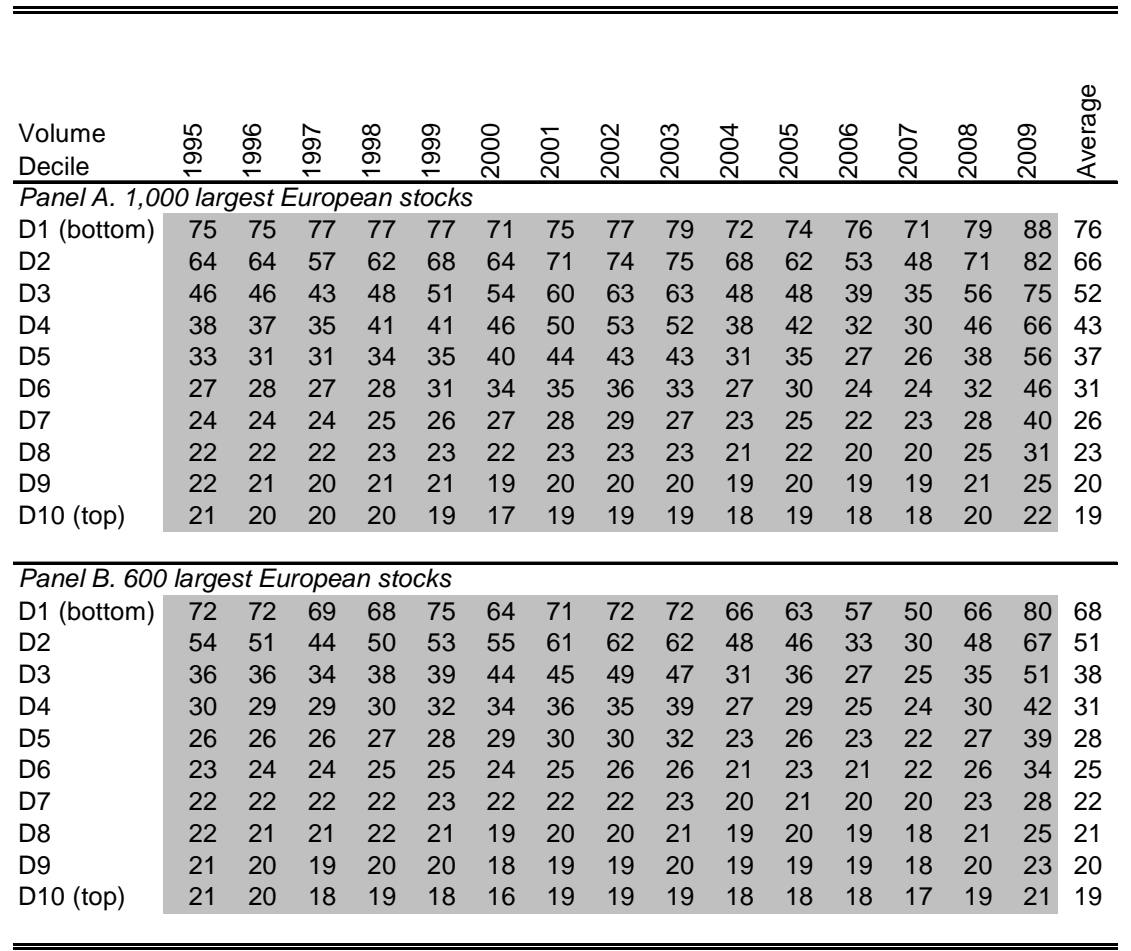


TABLE 4. Profitability of standard reversal investment strategies for the $1,500,500$ and 100 largest U.S. stocks.

Table 4 presents the weekly gross and net returns of the long portfolio, the short portfolio, and the long-short portfolio based on reversal quintiles for the 1,500 (Panel A), 500 (Panel B) and 100 (Panel C) largest U.S. stocks relative to the equally weighted average return of the stock universe. In addition, the table presents the turnover of the long-short portfolio. Net returns for each stock are computed at each point in time by taking the trading cost estimates associated with the stock's volume rank using the schemes based on the Keim and Madhavan (1997) model and the transaction cost model of Nomura Securities listed in Tables 1 and 2. A minimum of zero is imposed for the transaction cost estimates resulting from the Keim and Madhavan model.

\begin{tabular}{|c|c|c|c|c|c|}
\hline & $\begin{array}{c}\text { Return long } \\
\text { (bps) }\end{array}$ & $\begin{array}{c}\text { Return } \\
\text { short (bps) }\end{array}$ & $\begin{array}{l}\text { Return long. } \\
\text { short (bps) }\end{array}$ & t-stat & $\begin{array}{c}\text { Turnover } \\
(\%)\end{array}$ \\
\hline \multicolumn{6}{|c|}{ Panel A. Standard reversal strategy for 1,500 largest U.S. stocks } \\
\hline Gross return & 29.9 & -31.6 & 61.7 & 8.7 & 677 \\
\hline Net return using KM estimates & -35.3 & 31.1 & -66.1 & -9.2 & $"$ \\
\hline Net return using Nomura estimates & -54.6 & 49.6 & -103.7 & -14.5 & $"$ \\
\hline \multicolumn{6}{|c|}{ Panel B. Standard reversal strategy for 500 largest U.S. stocks } \\
\hline Gross return & 35.3 & -36.4 & 71.9 & 9.1 & 688 \\
\hline Net return using KM estimates & 32.5 & -33.6 & 66.4 & 8.4 & $"$ \\
\hline Net return using Nomura estimates & -2.7 & 0.3 & -3.0 & -0.4 & $"$ \\
\hline \multicolumn{6}{|c|}{ Panel C. Standard reversal strategy for 100 largest U.S. stocks } \\
\hline Gross return & 43.7 & -40.3 & 84.2 & 9.8 & 711 \\
\hline Net return using KM estimates & 42.8 & -39.4 & 82.5 & 9.6 & $"$ \\
\hline Net return using Nomura estimates & 17.1 & -14.4 & 31.5 & 3.7 & $"$ \\
\hline
\end{tabular}


TABLE 5. Profitability of "smart" reversal investment strategies for the $1,500,500$ and 100 largest U.S. stocks.

Table 5 presents the weekly gross and net returns of the long portfolio, the short portfolio, and the long-short portfolio based on reversal portfolios containing 20 percent of the 1,500 (Panel A), 500 (Panel B) and 100 (Panel C) largest U.S. stocks relative to the equally weighted average return of the stock universe. In addition, the table presents the turnover of the long-short portfolio. The reversal portfolios are constructed using an approach that does not directly sell (buy back) stocks that are no longer losers (winners), but waits until these stocks are ranked among the top (bottom) 50 percent of stocks. Net returns for each stock are computed at each point in time by taking the trading cost estimates associated with the stock's volume rank using the schemes based on the Keim and Madhavan (1997) model and the transaction cost model of Nomura Securities listed in Tables 1 and 2. A minimum of zero is imposed for the transaction cost estimates resulting from the Keim and Madhavan model.

\begin{tabular}{|c|c|c|c|c|c|}
\hline & $\begin{array}{c}\text { Return long } \\
\text { (bps) }\end{array}$ & $\begin{array}{c}\text { Return } \\
\text { short (bps) }\end{array}$ & $\begin{array}{l}\text { Return long. } \\
\text { short (bps) }\end{array}$ & t-stat & $\begin{array}{c}\text { Turnover } \\
(\%)\end{array}$ \\
\hline \multicolumn{6}{|c|}{ Panel A. Smart reversal strategy for 1,500 largest U.S. stocks } \\
\hline Gross return & 27.7 & -31.9 & 59.8 & 8.8 & 325 \\
\hline Net return using KM estimates & -2.9 & -1.4 & -1.5 & -0.2 & " \\
\hline Net return using Nomura estimates & -10.9 & 6.8 & -17.6 & -2.6 & $"$ \\
\hline \multicolumn{6}{|c|}{ Panel B. Smart reversal strategy for 500 largest U.S. stocks } \\
\hline Gross return & 30.7 & -34.0 & 65.0 & 8.7 & 326 \\
\hline Net return using KM estimates & 29.4 & -32.7 & 62.3 & 8.4 & $"$ \\
\hline Net return using Nomura estimates & 13.7 & -16.8 & 30.5 & 4.1 & $"$ \\
\hline \multicolumn{6}{|c|}{ Panel C. Smart reversal strategy for 100 largest U.S. stocks } \\
\hline Gross return & 40.9 & -36.7 & 77.9 & 9.4 & 337 \\
\hline Net return using KM estimates & 40.5 & -36.3 & 77.1 & 9.3 & $"$ \\
\hline Net return using Nomura estimates & 28.6 & -24.4 & 53.1 & 6.4 & $"$ \\
\hline
\end{tabular}




\section{TABLE 6. Profitability of reversal investment strategies for the 1,000 , 600 , and 100 largest European stocks.}

Table 6 presents the weekly gross and net returns of the long portfolio, the short portfolio, and the long-short portfolio based on reversal strategies for the $1,000,600$ and 100 largest European stocks relative to the equally weighted average return of the stock universe. In addition, the table presents the turnover of the long-short portfolio. Net returns for each stock are computed at each point in time by taking the trading cost estimates associated with the stock's volume rank using the schemes based on the transaction cost model of Nomura Securities listed in Table 3. Panels A, C and E present the results using a standard portfolio construction approach that is long (short) in the 20 percent of stocks with the lowest (highest) returns over the past week. Panels $B, D$ and $E$ show the results for a slightly more sophisticated portfolio construction approach that does not directly sell (buy back) stocks that are no longer losers (winners), but waits until these stocks are ranked among the top (bottom) 50 percent of stocks.

\begin{tabular}{|c|c|c|c|c|c|}
\hline & $\begin{array}{c}\text { Return long } \\
\text { (bps) }\end{array}$ & $\begin{array}{c}\text { Return } \\
\text { short (bps) }\end{array}$ & $\begin{array}{l}\text { Return long. } \\
\text { short (bps) }\end{array}$ & t-stat & $\begin{array}{c}\text { Turnover } \\
(\%) \\
\end{array}$ \\
\hline \multicolumn{6}{|c|}{ Panel A. Standard reversal strategy for 1,000 largest European stocks } \\
\hline Gross return & 24.6 & -25.3 & 50.0 & 7.7 & 672 \\
\hline Net return using Nomura estimates & -113.4 & 106.5 & -217.5 & -33.4 & $"$ \\
\hline \multicolumn{6}{|c|}{ Panel B. Smart reversal strategy for 1,000 largest European stocks } \\
\hline Gross return & 28.2 & -27.6 & 56.0 & 9.0 & 319 \\
\hline Net return using Nomura estimates & -36.0 & 36.4 & -72.1 & -11.6 & $"$ \\
\hline \multicolumn{6}{|c|}{ Panel C. Standard reversal strategy for 600 largest European stocks } \\
\hline Gross return & 34.3 & -34.6 & 69.2 & 9.6 & 683 \\
\hline Net return using Nomura estimates & -81.3 & 76.8 & -156.9 & -21.8 & $"$ \\
\hline \multicolumn{6}{|c|}{ Panel D. Smart reversal strategy for 600 largest European stocks } \\
\hline Gross return & 35.0 & -34.2 & 69.5 & 10.0 & 323 \\
\hline Net return using Nomura estimates & -18.6 & 19.8 & -38.3 & -5.5 & $"$ \\
\hline \multicolumn{6}{|c|}{ Panel E. Standard reversal strategy for 100 largest European stocks } \\
\hline Gross return & 48.0 & -48.1 & 96.5 & 9.8 & 700 \\
\hline Net return using Nomura estimates & -24.9 & 22.9 & -47.7 & -4.9 & $"$ \\
\hline \multicolumn{6}{|c|}{ Panel F. Smart reversal strategy for 100 largest European stocks } \\
\hline Gross return & 46.3 & -43.8 & 90.5 & 9.5 & 332 \\
\hline Net return using Nomura estimates & 11.9 & -9.7 & 21.6 & 2.3 & $"$ \\
\hline
\end{tabular}


TABLE 7. Profitability of reversal investment strategies using a five-day rebalancing frequency.

Table 7 presents the weekly gross and net returns of the long portfolio, the short portfolio, and the long-short portfolio based on reversal quintiles using a five-day rebalancing frequency for the 1,500 (Panel A), 500 (Panel B) and 100 (Panel C) largest U.S. stocks. In addition, the table presents the turnover of the long-short portfolio. Net returns for each stock are computed at each point in time by taking the trading cost estimates associated with the stock's volume rank using the schemes based on the transaction cost model of Nomura Securities listed in Tables 1 (for the 1,500 largest U.S. stocks) and 2 (for the 500 and 100 largest U.S. stocks).

\begin{tabular}{|c|c|c|c|c|c|}
\hline & $\begin{array}{c}\text { Return long } \\
\text { (bps) }\end{array}$ & $\begin{array}{c}\text { Return } \\
\text { short (bps) }\end{array}$ & $\begin{array}{l}\text { Return long. } \\
\text { short (bps) }\end{array}$ & t-stat & $\begin{array}{c}\text { Turnover } \\
(\%)\end{array}$ \\
\hline \multicolumn{6}{|c|}{ Panel A. Standard reversal strategy for 1,500 largest U.S. stocks with a 5-day rebalancing frequency } \\
\hline Gross return & 18.6 & -22.5 & 41.2 & 7.3 & 306 \\
\hline Net return using Nomura estimates & -17.6 & 13.9 & -31.4 & -5.6 & $"$ \\
\hline \multicolumn{6}{|c|}{ Panel B. Standard reversal strategy for 500 largest U.S. stocks with a 5-day rebalancing frequency } \\
\hline Gross return & 20.2 & -23.7 & 44.0 & 7.1 & 310 \\
\hline Net return using Nomura estimates & 3.5 & -7.1 & 10.6 & 1.7 & $"$ \\
\hline \multicolumn{6}{|c|}{ Panel C. Standard reversal strategy for 100 largest U.S. stocks with a 5-day rebalancing frequency } \\
\hline Gross return & 25.3 & -26.7 & 52.2 & 7.9 & 315 \\
\hline Net return using Nomura estimates & 13.7 & -15.3 & 29.0 & 4.4 & $"$ \\
\hline
\end{tabular}


TABLE 8. Profitability of reversal investment strategies over subperiods Table 8 presents the weekly gross and net returns of the long portfolio, the short portfolio, and the long-short portfolio based on a reversal strategy over the period January 2000 to December 2009 (Panels A, B and C) and over our full sample period excluding the dot-com bubble from January 1999 to December 2001 and the credit crisis from January 2008 to December 2009 (Panels D, E and F). In addition, the table presents the turnover of the longshort portfolio. The reversal portfolios are constructed using an approach that does not directly sell (buy back) stocks that are no longer losers (winners), but waits until these stocks are ranked among the top (bottom) 50 percent of stocks. Net returns for each stock are computed at each point in time by taking the trading cost estimates associated with the stock's volume rank using the schemes based on the transaction cost model of Nomura Securities listed in Tables 1 and 2.

\begin{tabular}{|c|c|c|c|c|c|}
\hline & $\begin{array}{l}\text { Return long } \\
\text { (bps) }\end{array}$ & $\begin{array}{c}\text { Return } \\
\text { short (bps) } \\
\end{array}$ & $\begin{array}{l}\text { Return long. } \\
\text { short (bps) }\end{array}$ & t-stat & $\begin{array}{c}\text { Turnover } \\
(\%)\end{array}$ \\
\hline \multicolumn{6}{|c|}{ Panel A. Smart reversal strategy for 1,500 largest U.S. stocks over the period 2000 to 2009} \\
\hline Gross return & 10.5 & -22.6 & 33.2 & 2.7 & 317 \\
\hline Net return using Nomura estimates & -19.4 & 8.5 & -27.9 & -2.3 & $"$ \\
\hline \multicolumn{6}{|c|}{ Panel B. Smart reversal strategy for 500 largest U.S. stocks over the period 2000 to 2009} \\
\hline Gross return & 22.2 & -30.7 & 53.0 & 4.0 & 320 \\
\hline Net return using Nomura estimates & 7.1 & -14.9 & 22.1 & 1.7 & $"$ \\
\hline \multicolumn{6}{|c|}{ Panel C. Smart reversal strategy for 100 largest U.S. stocks over the period 2000 to 2009} \\
\hline Gross return & 40.0 & -38.3 & 78.6 & 5.5 & 329 \\
\hline Net return using Nomura estimates & 30.3 & -28.5 & 59.0 & 4.1 & $"$ \\
\hline \multicolumn{6}{|c|}{ Panel D. Smart reversal strategy for 1,500 largest U.S. stocks during non-crises periods } \\
\hline Gross return & 29.1 & -31.8 & 61.1 & 12.1 & 325 \\
\hline Net return using Nomura estimates & -10.4 & 7.4 & -17.8 & -3.5 & $"$ \\
\hline \multicolumn{6}{|c|}{ Panel E. Smart reversal strategy for 500 largest U.S. stocks during non-crises periods } \\
\hline Gross return & 27.5 & -29.6 & 57.3 & 10.6 & 326 \\
\hline Net return using Nomura estimates & 10.6 & -12.6 & 23.2 & 4.3 & $"$ \\
\hline \multicolumn{6}{|c|}{ Panel F. Smart reversal strategy for 100 largest U.S. stocks during non-crises periods } \\
\hline Gross return & 31.9 & -28.4 & 60.4 & 9.6 & 337 \\
\hline Net return using Nomura estimates & 19.1 & -15.7 & 34.8 & 5.5 & $"$ \\
\hline
\end{tabular}


TABLE 9. "Smart" portfolio construction using alternative trade rules. Table 9 presents the weekly gross and net returns of the long portfolio, the short portfolio, and the long-short portfolio based on reversal strategies relative to the equally weighted average return of the stock universe. In addition, the table presents the turnover of the long-short portfolio. The reversal portfolios are constructed using an approach that does not directly sell (buy back) stocks that are no longer losers (winners), but waits until these stocks are ranked above (below) the 30th (70th) percentile (Panel A); the 40th (60th) percentile (Panel B); the 60th (40th) percentile (Panel C); the 70th (30th) percentile (Panel D); and the 80th (20th) percentile (Panel E). Net returns for each stock are computed at each point in time by taking the trading cost estimates associated with the stock's volume rank using the schemes based on the transaction cost model of Nomura Securities listed in Table 2.

\begin{tabular}{|c|c|c|c|c|c|}
\hline & $\begin{array}{c}\text { Return long } \\
\text { (bps) }\end{array}$ & $\begin{array}{c}\text { Return } \\
\text { short (bps) }\end{array}$ & $\begin{array}{l}\text { Return long. } \\
\text { short (bps) }\end{array}$ & t-stat & $\begin{array}{c}\text { Turnover } \\
(\%) \\
\end{array}$ \\
\hline \multicolumn{6}{|c|}{ Panel A. Smart reversal strategy for 500 largest U.S. U.S. stocks using 30/70 trade rule } \\
\hline Gross return & 34.0 & -37.2 & 71.5 & 9.1 & 479 \\
\hline Net return using Nomura estimates & 8.1 & -11.9 & 20.1 & 2.6 & $"$ \\
\hline \multicolumn{6}{|c|}{ Panel B.Smart reversal strategy for 500 largest U.S. U.S. stocks using 40/60 trade rule } \\
\hline Gross return & 32.1 & -35.8 & 68.2 & 8.9 & 387 \\
\hline Net return using Nomura estimates & 11.5 & -15.4 & 27.0 & 3.5 & $"$ \\
\hline \multicolumn{6}{|c|}{ Panel C. Smart reversal strategy for 500 largest U.S. U.S. stocks using 60/40 trade rule } \\
\hline Gross return & 30.9 & -33.0 & 64.1 & 8.9 & 275 \\
\hline Net return using Nomura estimates & 16.7 & -18.5 & 35.2 & 4.9 & $"$ \\
\hline \multicolumn{6}{|c|}{ Panel D.Smart reversal strategy for 500 largest U.S. U.S. stocks using $70 / 30$ trade rule } \\
\hline Gross return & 28.1 & -30.5 & 58.7 & 8.6 & 225 \\
\hline Net return using Nomura estimates & 16.7 & -18.6 & 35.3 & 5.2 & $"$ \\
\hline \multicolumn{6}{|c|}{ Panel E. Smart reversal strategy for 500 largest U.S. U.S. stocks using $80 / 20$ trade rule } \\
\hline Gross return & 24.3 & -27.3 & 51.7 & 8.2 & 170 \\
\hline Net return using Nomura estimates & 15.8 & -18.3 & 34.2 & 5.4 & $"$ \\
\hline
\end{tabular}


TABLE 10. Fama-French regressions.

Table 10 present the coefficient estimates and adjusted R-squared values of Fama-French regressions of weekly gross and net returns of the long-short portfolio based on reversal portfolios containing 20 percent of the 1,500 (Panel A), 500 (Panel B) and 100 (Panel C) largest U.S. stocks on the FamaFrench risk factors (French, 2010) for market, size and value [see, e.g., Fama and French $(1993,1995,1996)]$ :

$$
r_{i, t}=a+b_{1} s R M R F_{t}+b_{2} S M B_{t}+b_{3} H M L_{t}+\varepsilon_{i, i},
$$

where $r_{i, t}$ is the return on reversal strategy $i$ in month $t, R M R F_{t}, S M B_{t}$ and $H M L_{t}$ are the returns on factor-mimicking portfolios for the market, size and value in month $t$, respectively, $a, b_{1}, b_{2}$ and $b_{3}$ are parameters to be estimated, and $\varepsilon_{i, t}$ is the residual return of strategy $i$ in month $t$. The reversal portfolios are constructed using an approach that does not directly sell (buy back) stocks that are no longer losers (winners), but waits until these stocks are ranked among the top (bottom) 50 percent of stocks. Net returns for each stock are computed at each point in time by taking the trading cost estimates associated with the stock's volume rank using the schemes based on the transaction cost model of Nomura Securities listed in Tables 1 and 2.

\begin{tabular}{|c|c|c|c|c|c|c|}
\hline & Alpha (bps) & t-stat & RMRF & SMB & $\mathrm{HML}$ & Adj.Rsq \\
\hline \multicolumn{7}{|c|}{ Panel A. Smart reversal strategy for 1,500 largest U.S. stocks } \\
\hline Gross return & 60.9 & 9.2 & 0.1 & -0.2 & 0.0 & $5 \%$ \\
\hline Net return using Nomura estimates & -16.3 & -2.5 & 0.1 & -0.2 & 0.0 & $5 \%$ \\
\hline \multicolumn{7}{|c|}{ Panel B. Smart reversal strategy for 500 largest U.S. stocks } \\
\hline Gross return & 66.8 & 9.1 & 0.1 & -0.2 & 0.0 & $3 \%$ \\
\hline Net return using Nomura estimates & 32.6 & 4.4 & 0.1 & -0.2 & 0.0 & $3 \%$ \\
\hline \multicolumn{7}{|c|}{ Panel C. Smart reversal strategy for 100 largest U.S. stocks } \\
\hline Gross return & 80.7 & 9.9 & 0.1 & -0.2 & -0.1 & $2 \%$ \\
\hline Net return using Nomura estimates & 56.1 & 6.8 & 0.1 & -0.2 & -0.1 & $2 \%$ \\
\hline
\end{tabular}

